\section{Eric O. Silva}

Georgia Southern University, U.S.A.

\section{Levels of Disagreement Over Contested Practices}

Abstract This article unravels the tangled threads of argumentation that can be found in public debate over institutional practices. An analysis of letters to the editor ( $n=1551)$ written about two contested practices (American Indian mascots and the exclusive teaching of evolutionary theory) uncovers three analytically distinct levels of disagreement in the discourse. In the first level, partisans debate the effects of keeping or eliminating the contested practice. This disagreement over consequences leads to a second disagreement over how the social criteria for adjudicating controversies apply to the situation. This application level sits atop a third foundational level of the discourse where partisans debate the nature of social reality and the definition of the rules.

Keywords Framing; Laminations; Indian Mascots; Evolutionary Theory; Intelligent Design

$\mathrm{T}$

fact that the same obdurate conditions can be interpreted in multiple ways stands among the most enduring and significant contributions of social science. Nowhere is this fact more evident than the various battles over the definition of contested practices - recognizable institutional conduct whose legitimacy has been challenged in the public sphere (see Silva 2007:245). Contested practices are as varied as abortion, segregation, teaching evolutionary theory, and sports teams' usage of Indian mascots. Sociologists have outlined a number of features of how people define these components

Eric O. Silva, Ph.D. UC Davis, is an Assistant Professor in the Department of Sociology and Anthropology at Georgia Southern University. His research focuses on how people define contested practices (e.g., Indian mascots, evolutionary theory, and immigration policy) in public communication.

email address: eosilva@georgiasouthern.edu of their world. ${ }^{1}$ In addition to being an importan subject of research, the notion that contested practices are socially constructed is also an importan feature of several courses taught by sociologists (e.g., social problems, social movements, gender, race and ethnicity)

Despite the substantial body of work produced af ter the "discursive turn," there is still much to learn about the ideational processes involved in the social construction of contested practices. This article focuses on one particular lacuna - the intertwined - yet, analytically distinct - levels of disagreement that exist in the discourse. We know that defender and advocates of the status quo will offer different versions of reality. They will not, however, be in complete disagreement. There will be some points on which adversaries will be in accord (Thomson

${ }^{1}$ These approaches have produced a variety of concepts, such as frames (e.g., Benford and Snow 2000), narratives (e.g., Po-
letta 1998), and discursive repertoires (Steinberg 1999).
2010). Moreover, there will be matters on which allies will quarrel (Benford 1993). Given this confusing situation, the analysis presented below answers the following question: What are the basic types of disagreement that exist in the discourse over contested practices?

This question was inductively unearthed and addressed by taking a somewhat uncommon approach - an analysis of a large number of letters to the editor (1551) published about two separate controversies - sports teams' use of Indian mascots and the teaching of evolutionary theory in public schools. Discourse analyses typically focus on a single case. A comparison of the discourse over two controversies allows one to transcend the matters that are specific to a particular dispute and observe the general or basic features of the discourse. In this instance, the comparative method demonstrates how discourse over contested practices will be composed of three levels of disagreement. At one level, there is a disagreement over what is occurring and what ought to occur. At a second level, partisans disagree about how the cultural rules for defining reality apply to the dispute over the contested practice. At a third level, participants in the discourse will describe the context that surrounds the controversy. These constructions of social context include definitions of the rules that are applied in the second level.

Awareness of these levels of disagreement will improve scholarly understanding of how partisans construct reality. The concepts articulated here should allow scholars to better organize the complex permutations of political discourse. Being "sensitized" (Blumer 1969) to these levels of disagreement should facilitate a more nuanced ap- proach to the study of discourse. That is, scholars can more readily observe the disagreement that exists within factions and the agreement that exists between factions. Correspondingly, we gain a more thorough understanding of the discursive processes that are involved in the definition of contested practices. Finally, these findings may have pedagogical value as attentiveness to these levels of disagreement can help scholars to explain disputes over contested practices to students.

The following section provides a description of the two cases and an explanation for why it is important to understand the levels of disagreement found in the discourse surrounding each contested practice. Next, the literature on "framing," as well as the data and methodology are discussed. The results of the analysis are then presented. Finally, the article concludes with a consideration of the relevance of these findings to future research

\section{Two Contested Practices}

Both the controversies over Indian mascots and evolutionary theory are examples of contested practices. Each will be briefly described before making an argument for the usefulness of doing a comparative analysis of them.

The Indian mascot controversy dates back to the late 1960s and early 1970s where students at Dartmouth College, Stanford University, Syracuse University, and the University of Oklahoma successfully protested their teams' Indian mascots (Spindel 2002). The issue has been discussed in the American media at the national level (Rosenstein 2001) and local level (Silva 2007; Callais 2010). While these Indian mascots have been defended by fans 
(King 2004; Staurowsky 2004), roughly two-thirds of the 1970s era mascots have been replaced (Pember 2007). In 2005, the National Collegiate Athletic Association (NCAA) ruled that teams with Indian mascots may not host or display the imagery at official post-season tournaments. The policy has succeeded in compelling a number of teams to retire their mascots. Some universities (e.g., Florida State University), however, have convinced the NCAA to allow them to retain their Indian mascot after demonstrating tribal support for it (Pember 2007; Staurowsky 2007)

While controversy over the place of evolutionary theory in American public schools goes back to, at least, the Scopes trial of 1925, I focus on its most recent phase that began in the 1980s, when antievolutionists sought to reduce the significance of evolutionary theory and/or to introduce the concept of "intelligent design" (ID) into the classroom (Numbers 2006; Binder 2007; Larson 2007). The thrust of the intelligent design argument is that the irreducible complexity found in natural structures points to the impossibility of unguided, incremental evolution; rather, it is more likely that an Intelligent Designer, who may or may not be the JudeoChristian god, guided the development of living things. The intelligent design movement has met resistance from those who are concerned about the quality of science education and those who believe that intelligent design, despite its claims to the contrary, represents a particular theological view. This movement was dealt a major setback in 2005 in Kitzmiller, et at. v. Dover Area School District, et al. when United States District Judge John E. Jones ruled inclusion of ID in public school biology classes to be unconstitutional (Kitzmiller v. Dover Area School District 2005).
By including two cases I hope to identify general discursive patterns. As such, I will be less interested in the particular features of each case and more focused on the observed patterning across cases (see Skocpol 1984). While teaching evolutionary theory and symbolizing sports teams with Indian imagery are very different types of institutional conduct, both are cases of contested practices. The legitimacy of each has been challenged in the public sphere. Both practices would continue unabated were it not for this challenge. As contested practices, both evolutionary theory and Indian mascots encounter support and opposition in the public sphere. This pattern of support and opposition is, in part, a result of the fact that a contested practice, be it the war in Afghanistan, affirmative action, voter identification laws, or the cases under consideration here, are embedded within a complex mélange of cultural logics. The controversy over Indian mascots is discussed in terms of the autonomy of school boards, community traditions, the First Amendment, and racism. Likewise, conflict over evolutionary theory involves lofty notions of censorship, religious freedom, and sound science. Given the number of abstract issues that are in play, there should be multiple paths by which advocates for change or retention travel to justify their position. If there are multiple paths, then there are likely to be important within faction disagreements (see Benford 1993). Correspondingly, there are likely to be points on which people who take pro and con points agree with each other, as well (see Thomson 2010). One way to better understand the discourse over any particular contested practice is to discover the patterned places in which partisans disagree with each other in all contested practices. To discover these basic types of disagreement, I turn to a theoretical literature that is well suited to the task.

\section{Frames and Lamination}

Numerous students of social movements have drawn upon Erving Goffman's (1974) theory of framing to describe how partisans attempt to define contested practices (Benford and Snow 2000; Snow 2004). ${ }^{2}$ Frames are "the statement(s) required to place and to understand a strip of activity: 'on the beach,' 'play fighting,' 'an $18^{\text {th }}$-century drawing room” (Scheff 2005:381). In everyday life, this sort of framing is relatively unproblematic, but in political discourse partisans will offer competing framings of the same situation (Snow 2004). This sort of contentious framing is readily apparent in the cases analyzed in this article. Mascot defenders often frame the practice as an "honor." While others claim that it is "harmless" or an "important tradition." Detractors frame it as "racist." Evolutionists define intelligent design as "non-scientific" or "religious." Many anti-evolutionists use the frame of "scientific" to define intelligent design. While the concept of framing provides a way to look at how people construct reality, it is a lesser known component of the theory that will help to disentangle the various points of agreement and disagreement between factions.

There are often multiple levels or, in Goffman's (1974) parlance, "laminations" to the definition of the situation. ${ }^{3}$ To explain this concept Goffman (1974:183) references "the play within a play" that occurs in Hamlet. One lamination is an audience

${ }^{2}$ While social movement scholars do not use the term "contested practice," nearly all social movements exist to protect or change some type of institutional practice. I use the broad term "contested practice" rather than "social movement" because the various efforts to protect or eliminate contested practices may or may not meet the criteria of a social movement (see Snow and Soule 2010 for this criteria).

Despite the fact that only a few of the nearly six hundred pages of Frame Analysis deal explicitly with the concept of Ta watching a theatrical production of Hamlet. Inside of that lamination is a second lamination - the fictional world created by the play. Within this theatrical world lies a third lamination wherein another world - the play within a play - exists. For another example, think of a lecture in an introductory sociology course. One lamination would be the transference of wisdom about "mores" and "norms." Suppose that within the lecture hall two students engage in a bit of quiet flirtation. On top of the lecture lamination is a second "flirtation" lamination. While Goffman's theory helps to conceptualize the multiple layers of reality, his articulation of laminations is not readily applicable to the analysis of public discourse over contested practices. In fact, for decades, laminations were all but ignored by the myriad of frame analyses of political discourse.

Mark M. Hedley and Sarah A. Clark (2007) revisited the concept of laminations and succeeded in adapting it to this task. They analyzed the discussion that developed in a university email listserv over a planned protest of the United States' 2003 invasion of Iraq Hedley and Clark (2007) found that an initial debate over the acceptability of the specific protest developed three additional laminations - the legitimacy of anti-war protests, the rightfulness of the war, and whether the listserv was the best place for the discussion. Based on their analysis of the discourse, they argue that each sub-debate that developed in the discourse represents a distinct lamination. They show that public debates over contested practices (such as the acceptability of teaching evolutionary theory or using Indian mascots) will spawn a number of subdebates which take the form of laminations within the discourse. Moreover, people who agree on a dispute found in one lamination may disagree on a point being debated in another lamination (Hedley and 
Clark 2007). Hedley and Clark's (2007) demonstration of how sub-debates represent laminations within the discourse leads to the question that this article will attempt to answer: What types of laminations will typically develop in public debates over contested practices? These typical laminations are the general points on which partisans will disagree as they vie to offer competing definitions of evolutionary theory or Indian mascots. While answering this question, I sought to learn more about the nature of laminations. Are the laminations of the discourse independent of each other or are they somehow connected? Do new laminations eclipse previous laminations (as suggested by Hedley and Clark [2007]) or is there overlap? If the disagreements build upon each other, they can be said to be levels of disagreement. I now turn to the data and methodology used for uncovering and answering these questions.

\section{Methods and Data}

Letters to the editor are the ideal data for examining public discourse over contested practices. First, they are a "mediated public sphere," where partisans disseminate their political opinions (Perrin 2005:171). These letters represent one of the best opportunities for non-elites to reach a wide audience (Perrin 2005). Using letters to the editor allows one to avoid the "elite bias" that sometimes distorts studies of political discourse (see Benford 1997). Finally, while letters to the editor may not represent public opinion, they are an indicator of the range of arguments that may be found within a political culture (Perrin 2005).

My source of letters was the Newsbank database (http://infoweb.newsbank.com), which includes newspapers of varying circulations. For both conflicts I sought letters to the editor published in American newspapers that advocated a pro or con position. Between November 2004 and January 2005, I searched for documents that contained the words "Indian" and "mascot" within twenty words of each other and also the words "letter" or "letters" to obtain 471 letters written in favor of mascot retention and 278 that called for elimination. There were 9 letters that addressed the issue without clearly lending support to either side. I classified a letter as pro-mascot if it stated that it wanted an Indian mascot retained and/or if it provided frames that supported keeping the mascot or undermined those that called for change (and vice versa). The letters come from 104 newspapers. These newspapers include national publications (The Christian Science Monitor and USA Today) and ones centered in 32 states and Washington, D.C.

The controversy over evolutionary theory is considerably larger than the mascot debate, and, consequently, my inquiries (conducted intermittently between February 2007 and January 2009) yielded thousands of pages of letters and other material published between 1985 and 2008. Given the enormous amount of material, I reduced the sample to a manageable level by using a random sampling procedure of the collected data that yielded 793 letters published between 1987 and 2008. There were 429 letters that aided the cause of exclusively teaching evolutionary theory and 325 that lent support to reducing the prominence of evolutionary theory. There were 39 letters that did not seem to help one side over the other. ${ }^{4}$ These data

${ }^{4}$ In the initial round of analysis, if a letter did not seem to be of "unclear." I then gave these unclear letters a second look to see if a position could be discerned. For instance, letters that took a theistic evolutionary approach were difficult to code as pro or con. In these cases, if the letter seemed to emphasize interpreting evolutionary theory as consistent with Christia theology and it did not call for science classes to discuss theoegred for 政, I I categorized anti-evolution. were collected using the search terms "intelligent design" and "creationism," and "letter" or "letters." I collected the letters incrementally by searching for letters published in a delimited time period (e.g., 1989). Beginning with my searches for letters written in 2005, I added in the search terms "Darwin" and "evolution." 5 The letters were published in 199 newspapers in 46 states and Washington, D.C.

In general, I followed the procedures outlined by John Lofland and colleagues (2006) to analyze the data. At the outset, I wanted to take advantage of the comparatively large size of the sample and the use of two cases to contribute to the basic theory of political framing. I began by detailing the types of justifications that were used for retaining Indian mascots. I then compared these pro-mascot framings with anti-mascot framings. Next, I compared the framings for and against the retention of Indian mascots with the framings for and against evolutionary theory. Based on these comparisons I began to establish a scheme for the general forms of framing that could be found in the data. I then compared these general types that I had found with the types described in the framing literature. I determined the general framing forms I had found were best thought of as laminations. That is, certain framings seemed to be geared towards different laminations in the discourse. These different laminations housed distinct sub-debates. At this point, I arrived at my research question of discovering the basic types

Adding in the new search terms increased the diversity of the sample, but it may also have distorted the proportions of certain types of arguments. This distortion is, however, $\mathrm{mi}$ nor as there are only 32 letters in the reduced sample which were collected using the additional search terms (29 letters contained the term "Darwin" but not "intelligent design" or
"creationism"). of disagreements that exist within the discourse That is, how are the types of laminations found in the Indian mascot discourse similar to the types of laminations found in the evolutionary theory discourse? Once I uncovered the basic types of laminations, I used the qualitative software program, NVivo, to re-code the data for the types of laminations that could be found in each letter. In this final round of analysis, I was able to confirm that there were in fact three levels of disagreement. Given that laminations are a relatively underdeveloped concept, I also probed the data further to discover the general features of these laminations and the ideational relationship that exists between laminations.

\section{Findings}

The analysis uncovered three basic disagreements: an effects disagreement, an application disagreement, and a foundational disagreement. Each mode of disagreement is housed within a specific lamination of the discourse. In the first lamination, partisans disagree over what is occurring and what should occur. In a second lamination lies a dispute over how cultural rules for adjudicating cultural conflicts apply to the matter at hand. The frames deployed in the application lamination support the frames used in the effects lamination. Finally, there is the foundational disagreement which exists in a third lamination of the discourse. The frames deployed in this lamination are used to construct the social context that surrounds the contested practice. This discussion of context usually includes articulations of the rules that are applied in the second lamination. I will explicate these levels of the discourse with some empirical examples. 


\section{Effects Lamination}

The effects lamination includes framings of what is happening and what "ought" to occur. ${ }^{6}$ In the evolutionary theory discourse, partisans make a number of claims about the effects of exclusively teaching evolutionary theory, the potential effects of reducing the instruction of evolutionary theory, and/or teaching an alternative, such as ID. One such claim is that teaching alternative theories alongside evolutionary theory would improve student learning. For example:

[t]he bottom line is we can continue to call each other names, or we can put the childish antics aside and encourage our youths to form their own thoughts by teaching them both views and encourage them to think for themselves. (Anchorage Daily News [AK], July 22, 2005, italics added)

The italicized portion of the quote addresses the effects lamination by claiming that changing the status quo would have the consequence of pushing students to "think for themselves." The author is speaking to the results of choosing one path or another. The italicized portion is not explaining how the criteria for independent thinking apply to this particular instance, so it is not addressing the application lamination. Likewise, it is not explaining why independent thought is a valuable goal or what would constitute the criteria for independent thinking, so it is not addressing the foundational lamination.

${ }^{6}$ It is in this lamination where we see what David A. Snow and Robert D. Benford (1988; see also Entman 1993) refer to as a diagnostic framing (assigning blame), prognostic framing a diagnostic framing (assigning blame), prognostic framing
(presenting solutions), and motivational framing (giving reasons to participate). While these are different framing tasks, I categorize them together because they all contain the common denominator of relating to the desirability of pursuing a given line of action. Moreover, in practice, diagnosis and
prognosis are often tightly coupled.
The effect of reducing evolutionary theory's hegemony is a point of disagreement in the effects lamination. For example:

[t]hose who value religious freedom should know that the intelligent design proponents' goal is not to promote alternative scientific theories. Their goal is to drive a wedge into the wall separating church and state and to ultimately bring down that wall. (Cincinnati Enquirer [OH], June 19, 2002:7C, italics added)

In the italicized portion of this excerpt, the author addresses the effects lamination by claiming that teaching ID would not have the outcome of "promot[ing] alternative scientific theories," but would instead have the consequence of breaching the "wall separating church and state." If the statement included a discussion of how to use the rules governing the relationship between science, religion, and public schools, it would be addressing the application lamination. If the statement included a more thorough discussion of why church and state should be separated in the first place or explaining the criteria of the rule, it would be a contribution to the foundational lamination. These are just two of the estimated results. This level of the discourse is replete with estimates including: teaching evolutionary theory is necessary for students' education evolutionary theory does not threaten faith in god, evolutionary theory does conflict with faith in god, excluding ID is censorship, and so on.

This type of disagreement also exists within the mascot discourse. In the discourse over Indian mascots the effects lamination includes claims that the imagery is an honor, that it is racist, that community unity depends on it, that the mascot is harmless, and that removing the Indian mascot will be harmless. For example, a mascot supporter argues, "[t]he wonderful chief tradition links many generations of Illinois, including my uncle, daughters, some of my dearest friends, and me" (Chicago Sun-Times [IL], March 8, 2001:30). This author is defining the mascot as an important tradition for the people represented by the team. This assemblage of frames defines the practice as positive and worthy of retention. Another mascot defender writes, "[i]t is laudatory rather than belittling that some professional baseball and football teams and colleges...use Native American names" (Times-Picayune [LA], November 5, 1995:C2). By contrast, a mascot opponent writes, "[t]his behavior is racist; it trivializes our culture and belittles us as a people" (Bangor Daily News [ME], October 18, 1997, italics added). In the italicized portion, this author asserts that the practice is disrespectful towards Indian people and culture. Taken together, these three authors have provided three distinct versions of the consequences of Indian mascots.

To some extent, this level of the discourse is self-contained; for some people, the effects lamination presents unambiguous choices. The decision between defining Indian mascots as an important tradition and Indian mascots as racist will (likely) be clear for certain people. While I do not have any evidence for how anyone actually interprets the discourse about these controversies; logically, if a person is concerned about the sense of tradition fostered by a mascot and he/she does not care about racial discrimination, then, it does not make sense that he/she would care about how one arrives at the conclusion that the practice is racist. There would be no reason for him/her to move on to the second level of the discourse as he/she could construct his/her position towards the contested practice by taking each side's claims at face value. Likewise, if a person does not care at all about Christianity, he/she would not be concerned that evolution- ary theory is a threat to Christian faith. Accordingly, he/she would not need to learn the ways of framing evolutionary theory as a non-threat to religion. In either case, there would be no need for this hypothetical man or woman to travel to the second level of the discourse. By contrast, if a person does care about the goals of promoting team spirit and the goals of being non-racist, or the goals of teaching sound science and not undermining Christian faith, he/she would logically need to compare the ways determining what is happening. He/she might also need to decide how to prioritize or reconcile incompatible goals. The second and third levels of the discourse are where people debate how to think about these sorts of things.

\section{Application Lamination}

The application lamination forms as partisans try to explain how one should assess the diametrically opposed claims made in the effects lamination. In doing so, they move beyond a dispute over the definitions of the situation - to a contest over how to define the situation. It is in this second lamination where partisans demonstrate how they think the rules for interpreting reality apply to the interpretation of the contested practice.

In the discourse over evolutionary theory, partisan would draw on standards derived from the institutions of law, science, and religion. For illustrative purposes, I will focus on how both sides would attempt to apply scientific criteria to their definition of the situation. For example, an anti-evolutionist argues:

[t]he remarkable complexity and precision of life at the molecular level, the enormous gaps in the fossi record, the almost complete absence of transitiona life forms, and the obvious designs that abound in the 
universe all present serious problems for the naturalist theory of purposeless, unguided change. (Buffalo News [NY], October 23, 2005)

This author explains how his definition of evolutionary theory fits with scientific rules (i.e., the need for empirical evidence). One of his claims is that life's microscopically observable "complexity and precision" is evidence against evolutionary theory. He and other anti-evolutionists who make this argument are seeking to influence how uncontroversial evidence should be scientifically interpreted. Of course, evolutionists would counter this assertion: "[t]he amazing complexity and intricacy of life and its processes are, by themselves, not evidence of a creator or intelligent design" (Register-Guard [OR], May 28, 2005). This evolutionist agrees with the anti-evolutionist that complexity is observable, but disagrees about how to scientifically apply this observation to the evaluation of evolutionary theory and ID. The above anti-evolutionist also notes that evolutionary theory has not been supported by the predicted discovery of "transitional life forms." This framing is also addressed by evolutionists:

[s]eeing arguments using bogus science is frustrating and exasperating. Challenges such as "Show me the transitional fossils!" are merely ruses. Information is available to anyone who cares enough to take the time to look it up (here are two freebies - Archaeopteryx and Epihippus). (Daily Herald [IL], May 7, 2000:17)

This evolutionist responds to anti-evolutionist claims (such as the one quoted above) that evolutionary theory is undermined by absence of "transitional fossils" by mentioning two such examples. Taken together, these excerpts show that some evolutionists and anti-evolutionists are in agreement about the rule that scientific data should be used to define the situation (not all anti-evolutionists take this position). These letter writers disagree about how this rule applies to the situation. These claims are not directly addressing the effects lamination because they do not predict what will happen if evolutionary theory is exclusively taught. Rather, they are addressing how to apply scientific rules to the evaluation of evolutionary theory. This represents not just a disagreement about what should happen but a disagreement about how to use the same standards to interpret the practice. Note that they are not discussing whether science should be used to define the practice or what science consists of - that is the sort of debate that occurs in the foundational lamination.

The application lamination can also be found in the mascot discourse. Oftentimes both sides seemed to be in agreement that racial discrimination is undesirable. The effects lamination contained incompatible estimations on whether Indian mascots are a violation of anti-racist norms. Several mascot supporters would argue that the practice was not an instance of racial discrimination. Mascot opponents would argue that the practice had the effect insulting and/or dehumanizing a racial minority. For example:

...there are more white mascots in college and pro sports than American Indians. Just to name a few - Fightin' Irish, Spartans, Trojans, Cowboys, Cavaliers... These seem to be perfectly acceptable, and so should American Indian mascots. (State Journal Register [IL], November 20, 1991:4)

We would be shocked if someone put on a public minstrel show, and rightly so. Dancing around in a cartoonish Indian suit to amuse sports crowds is no different. (Los Angeles Times [CA], May 4, 2002:B22)
These statements represent contributions to the application lamination because they are arguing over how to apply standards for judging institutional practices to the definitions of Indian mascots. Both authors are, implicitly, drawing on the same abstract social rule - racist practices should be discontinued. However, they are making different arguments about how to apply this rule - the first author applies the rule by comparing Indian mascots to white mascots, which are acceptable practices. By making this comparison, he is not only claiming that the practice is harmless, he is also making an argument about how to use the social rules governing the practice - if it is acceptable to use white mascots, it is also acceptable to use Indian mascots. The second author compares Indian mascots to the patently disrespectful and antiquated practice of whites performing in "blackface" in Jim Crow era minstrel shows. He is going beyond the effects lamination to demonstrate how the situation should be defined. A comparison of these analogies shows that they both agree with anti-racist norms. They support their position in the effects lamination by offering different ways of applying anti-racist norms to the contested practice. It would be a contribution to the foundational lamination if either quotation included a full articulation of the rule that is being used or justification for why the rule should exist.

A social rule that was drawn on by both sides of both debates is that certain people have a privileged authority to judge contested practices. This rule was applied through the use of "credentialing" (Coy and Woehrl 1996) wherein partisans would tout their own or their allies' authority. For example:

[a]s a 1979 graduate of South Stokes High School and a descendant of mixed-blood heritage, including Cherokee, English, German, Scots, and Dutch, I say leave the Saura mascot alone. (Winston-Salem Journal [NC], April 9, 2003:A12)

Since the 1980s...an increasing number of anthropologists, biologists, astronomers, and scientists have recognized the shortcomings of the Darwinian theory as well as the evidence of "intelligent design" in our planet and the universe. (Stuart News [FL], September 7, 1998:A8)

Here, the first author is using two identity frames (partial Native American and alum) to back her claim that the mascot should be retained. The second author asserts that ID is accepted by people with the authority to judge theories. Neither author substantiates why certain identities should be endowed with a privileged voice (which would be a contribution to the foundational lamination). Instead, they address the application lamination by asserting a particular rule - that the views of people with greater authority should be given more consideration than those without such authority - better applies to themselves than to their opponents. By implication, others should give their contributions to the effects lamination greater consideration.

Similarly, partisans in both debates would draw on this rule by impugning the character of their opponents. For example, an anti-evolutionist "vilifies" (McCaffrey and Keys 2000) the above-mentioned Judge Jones (who ruled against introducing ID to high-school students in Dover, PA) as having an "arrogance" that "defies understanding" (Tennessean [TN], January 2, 2006). Likewise, an author in the Indian mascot controversy addresses the application lamination by undermining the character of his opponents by framing them as "childishly stubborn" (Chicago Sun-Times [IL], February 7, 2000:24). When letter writers discuss the characteristics of the people 
who support or oppose their position, they are engaging a debate about how the general standards of authority apply to the adjudication of a particular dispute.

The application lamination is analytically distinct from the effects lamination and foundational lamination. In the effects lamination partisans answer the question of what should occur. In the application lamination they debate how to use the cultural norms that govern the interpretation of reality. In the application lamination, when anti-evolutionists and evolutionists disagree about how to interpret empirical evidence, they are, at least publicly, in agreement about the rule requiring the use of empirical evidence. As partisans begin to elaborate upon the basis and definition of these rules (e.g., answering the questions "what constitutes empirical data?" or "why should we care about empirical data?"), they move away from the application lamination towards the foundational lamination.

\section{Foundational Lamination}

In the foundational lamination partisans outline their version of the surrounding cultural and historical context. The frames given in the foundational lamination are more abstract than the ones given in the effects lamination or application lamination. ${ }^{7}$ These abstract framings include the articulation of the general rules that are used in the application lamination and a justification for using one set of standards versus another. As partisans move from the effects lamination to the foundational lamina-

This is the lamination where "master frames," the broadbased cultural ideas from which "movement-specific "frames are derived (Snow and Benford 1992), are fully articulated and justified rather than cited. However, not all frames given in contributions to this lamination are rather obscure. tion, they oftentimes use frames that are similar to the ones proffered by some of their opponents and different from those used by many of their allies.

The evolutionary theory discourse developed a robust foundational lamination where partisans debated the general definition of the First Amendment to the United States Constitution, the value and role of religion, as well as the efficacy and nature of science. To describe this lamination, I will focus on how partisans outlined the scientific criteria that were used in the application lamination. Some authors on both sides of the debate framed science as being (or that it should be) honest, openended, and politically neutral:

[r]eal scientific theories are open-ended ideas that attempt to answer the mysteries of the universe. They are meant to encourage a healthy debate among scientists until the theory can be proven beyond a reasonable doubt. (Capital [MD], February 20, 2006)

Science is supposed to approach knowledge with an open mind, not stubbornly to refuse to listen to any suggestion that the prevailing theory could be wrong. The inquiring scientific mind should be open to ideas and observations... (Manhattan Mercury [KS], November 27, 2005)

Both of the above authors frame science as open to considering new ideas. They move on to disparate applications of this similar framing of science. The first author addresses the application lamination by claiming that ID does not meet the criterion that science should be open-ended. The second author applies the rule of openness in the exact opposite manner - that an open-minded science should consider the supernatural. Other framings of science could be found in the foundational lamination. Some antievolutionists would argue that science is not openended. For example: [a]ware or not, all scientists embrace faith and religion when they make value, worth, and benefit judgments. What scientist does not integrate his science with his personal world view, theistic, or otherwise? (Sacramento Bee [CA], December 27, 2005)

This post-modern author speaks to the foundational lamination by framing scientists as inherently biased. Based on this framing of science, he argues, in the application lamination, that scientists should not have the authority to invalidate ID because religion and science are inseparable. Anti-evolutionists, then, were able to make similar contributions to the effects lamination (i.e., framing evolutionary theory as needing to be reduced) that were based on disparate constructions of science.

The foundational lamination was also found in the discourse over Indian mascots. This lamination contained disagreements over the construction of Native Americans and their attendant rights, the autonomy of local school boards, the First Amendment to the United States Constitution, and the definition of mascots. For the purpose of describing the foundational lamination, this section will focus on the various definitions of mascots that were proffered. Unsurprisingly, mascot opponents and supporters proffered contrasting definitions of mascots. For example, a critic of Indian mascots writes, "mascots are not human beings, they are good luck tokens" (San Antonio Express-Neww [TX], November 10, 2001:10B). This author is framing mascots as non-human "good luck tokens." Such a definition facilitates the construction of the mascot as racist in the application lamination. If mascots are not humans, one can argue that using a race of people as a mascot is dehumanizing. The comparison of Indian mascots to "blackface" - discussed in the application lamination - fits with this conceptualization of mascots.
The above framing of the general practice of using mascots contrasts with pro-mascot writers who define mascots in a way that can include humans. For example:

[b]y definition, a mascot brings "good luck." I doubt "Redskin" was chosen to degrade or make fun of but rather to bring pride, strength, and wisdom to Arvada High School's students. (Rocky Mountain News [CO], April 28, 1993:42A, italics added)

The author contributes to the foundational lamination in the italicized portion when she defines mascots as something that "brings 'good luck."' She then moves on to the application lamination where she applies the positive abstract definition of mascots in general to the use of Indian mascots in particular. The comparison of Indian mascots to other human mascots is in accord with this positive depiction of mascots.

Both of the above examples claim that mascots are connected to notions of good luck. While the first example does not allow for the possibility of people, including Native Americans, to be used, the second definition is constructed to include humans. The discourse, then, has reached a third level where partisans are now offering different articulations of the rules.

An interesting property of this third level of the debate is that people who call for the same policy will sometimes define the rules differently. For example, a mascot supporter writes:

I would like to remind you that a human being isn't really a mascot. A mascot is something like Florida's Albert the Alligator ... The Seminole is the symbo of Florida State University, in honor of the only un- 
conquered tribe of Indians that lived in the United States. (Atlanta Journal Constitution [GA], May 20, 2001:E2, italics added)

This pro-mascot author's definition of mascots is closer to the one provided by the above anti-mascot author as both define mascots as something that cannot be human. That is, the two pro-mascot authors disagree at the foundational level while the pro-mascot and anti-mascot authors agree at the foundational level. It is at the application level where the second pro-mascot author and the antimascot author part ways. That is, despite agreeing at the foundational level that mascots cannot be people, they disagree at the application level about how the rule of mascot applies to the judgment of using Indian mascots. The anti-mascot author claims that, based on the rule that people cannot be mascots, Indian mascots are not acceptable. The pro-mascot author claims that because people cannot be mascots the contested practice cannot be considered a mascot, but it is allowable.

\section{Discussion and Conclusion}

The comparison of two large samples has demonstrated the existence of three laminations which house three levels of disagreement in the discourse over contested practices. These findings provide several scholarly contributions. The most general contribution is untangling the various types of disagreements. It is one thing to be able to recognize the complexity of the discourse and be aware of the fact that political factions cannot be understood in monolithic terms. It is another thing to be able to practically organize this complexity. This finding will help sociologists who are studying any particular contested practice to do so.
Knowledge of these levels of the discourse has pedagogical value. It provides a means for scholars to dissect the cultural disputes that we seek to explain to students. Whether the contested practice is evolutionary theory, Indian mascots, affirmative action, war, or abortion a discussion of each level of the disagreement can help to facilitate student learning by identifying the stances that people may take in each of the basic points of disagreement. Doing so will allow scholars to facilitate student learning without over-simplifying matters. For instance, to describe the controversy over evolutionary theory, a professor could outline the various frames that exist in the foundational lamination - for example, the disparate definitions of science. He/she could then discuss the various applications of these contrasting definitions, making note of the fact that some anti-evolutionists and evolutionists use the same definitions of science but to different ends. Finally, a discussion of the effects lamination would show students that, indeed, there are anti-evolutionists who seem more concerned about protecting a faith in a literal interpretation of the Bible than they are about maintaining a high quality science education, but that other anti-evolutionists frame their opposition in terms of wanting to improve science education. Likewise, this lecture would show evolutionists who seem to hope that evolutionary theory will undermine faith in the supernatural and evolutionists who conclude that evolutionary theory should not impact one's belief in god.

Similarly, such a presentation on the Indian mascot controversy would demonstrate the various ways that partisans define foundational issues, such as the rights of Native Americans, athletic teams, and their fans. For instance, the professor would show that mascot supporters and critics define Native Ameri- cans as having endured hardships, as an accomplished people worthy of respect, and as undeserving of special consideration. He/she would show the various applications of these foundational ideas. That is, some mascot supporters define Native Americans as worthy of respect and therefore, worthy of having the honor of being the symbol of an athletic team. There are also mascot critics who define Native Americans in positive terms but use this positive framing of $\mathrm{Na}-$ tive Americans to argue that Indian mascots should be discontinued because the mascot is not respectful. Other mascot supporters hold that Native Americans are undeserving of any special consideration and therefore, Native Americans who oppose Indian mascots should be ignored. A discussion on the effects lamination would explain how a number of consequences, such as honor to Native Americans, disrespect to Native Americans, and the sustenance of community tradition, are bandied about.

This sort of explication of the discourse over contested practices will help students to understand the various positions that people take, as well as the logic by which people arrive at those positions. In so doing, students will gain insight about how they justify their opinions. They will also obtain a deeper understanding of how others are able to take positions that differ from their own

Uncovering the existence of these three laminations improves our knowledge of the discursive processes involved in the construction of contested practices. More specifically, this study demonstrates a previously unacknowledged decision confronting partisans - those who seek to influence public opinion must choose how much space to devote to each lamination. For example, if an author feels that the audience is already aware of the contending ways of applying social rules, he/she would spend more time discussing how these rules are constituted. This choice is a basic component of how people actively define contested practices, and to this point it has largely been ignored. Scholarship has suggested that frame articulation (i.e., providing support for one's frame) is a predictor of political success (Cress and Snow 2000; McCammon 2009). By identifying the basic laminations of political framing, we gain a fuller sense of what frame articulation requires.

This article provides a clearer picture of the role of laminations in political discourse. Laminations will not only develop, they will do so in a predictable fashion. Moreover, certain laminations build upon and support each other in the discourse. Contrary to the idea that laminations come to completely (if only temporarily) obscure pre-existing laminations (Hedley and Clark 2007), we can see that laminations may only partially cover pre-existing ones. The three types of laminations often coincided within a particular letter. This property of laminations can be found in other, non-politicized interactions. As new features of an interaction develop, the old laminations may still remain. To return to Goffman's (1974) example of Hamlet, the audience members watching the play that occurs within Hamlet should be aware of the fact that they are watching two plays at once. The first play is only partially obscured by the second.

Certainly, this article has left many relevant questions unanswered. While it is clear that authors must choose which laminations to address, it did not - and could not - show if this rhetorical choice has any influence on how a reader defines the contested practice. Likewise, this cross-sectional analysis does not show us whether or not the proportion 
of space devoted to each level of disagreement remains static or if one type of lamination may become more prominent over time. Because the above analysis was dedicated to demonstrating the existence of these three levels of disagreement, I was not able to fully describe the variety of frames used at each level of the discourse or the frequency with which each frame appears. This type of description would show the predominant logics used by each side. A number of such analyses would help to develop our knowledge of the culture of the public sphere. While there is much that we still do not know about how people

\section{References}

Benford, Robert D. 1993. “Frame Disputes within the Nuclear Disarmament Movement." Social Forces 71(3):677-701.

Benford, Robert D. 1997. "An Insider's Critique of the Social Movement Framing Perspective." Sociological Inquiry 67(4):409-430.

Benford, Robert D. and David A. Snow. 2000. "Framing Processes and Social Movements: An Overview and Assessment." Annual Review of Sociology 26:11-39.

Binder, Amy. 2007. "Gathering Intelligence on Intelligent Design: Where did it come from where is it going, and how should progressives manage it?" American Journal of Education 113(4):549-576.

Blumer, Herbert. 1969. Symbolic Interaction: Perspective and Method. Berkeley, CA: University of California Press.

Callais, Todd M. 2010. “Controversial Mascots: Authority and Racial Hegemony in the Maintenance of Deviant Symbols." Sociological Focus 43(1):65-81.

Coy, Patrick G. and Lynne M. Woehrle. 1996. “Constructing Identity and Creating Oppositional Knowledge: The Framing Processes of Peace Movement Organizations during the Persian Gulf War." Sociological Spectrum 16(3):287-327. interpret contested practices, it is my hope that this article will facilitate this ongoing effort.

\section{Acknowledgements}

An earlier version of this article was presented at the 2008 meeting of the Society for Symbolic Interaction in Boston, MA. I wish to thank Lyn Lofland, Larry Griffin, Laura Grindstaff, David Snow, and anonymous reviewers for their suggestions on earlier drafts. I would also like thank Cory Lowe and Marlaina Dreher for their work as research assistants.

Cress, Daniel M. and David A. Snow. 2000. "The Outcomes of Homeless Mobilization: The Influence of Organization, Disruption, Political Mediation, and Framing." American Journal of Sociology 105(4):1063-1104.

Entman, Robert M. 1993. "Framing: Toward Clarification of a Fractured Paradigm." Journal of Communication 43(4):51-58.

Goffman, Erving. 1974. Frame Analysis: An Essay on the Organization of Experience. Boston: Northeastern University Press.

Hedley, Mark M. and Sarah A. Clark. 2007. "The Microlevel Discourse of Social Movement Framing: Debating Antiwar Protests on a University Listserv." Sociological Focus 40(1):26-47.

King, C. Richard. 2004. "This Is Not an Indian: Situating Claims about Indianness in Sporting Worlds." Journal of Sport and Social Issues 28(1):3-10.

Kitzmiller v. Dover Area School District. 2005. Case 4:04-cv02688-JEJ. Retrieved May 18, 2012 (http://ncse.com/files/ pub/legal/kitzmiller/highlights/2005-12-20_Kitzmiller decision.pdf).
Larson, Edward J. 2007. The Creation-Evolution Debate: Historical Perspectives. Athens, GA: University of Georgia Press.

Lofland, John et al. 2006. Analyzing Social Settings: A Guide to Qualitative Observation and Analysis, $4^{\text {th }}$ ed. Belmont, CA: Wadsworth Publishing Company.

McCaffrey, Dawn and Jennifer Keys. 2000. “Competitive Framing Processes in the Abortion Debate: PolarizationVilification, Frame Saving, and Frame Debunking." The Sociological Quarterly 41(1):41-61.

McCammon, Holly J. 2009. “Beyond Frame Resonance: The Argumentative Structure and Persuasive Capacity of Twentieth-Century U.S. Women's Jury-Rights Frames." Mobilization 14(1):45-64.

Numbers, Ronald L. 2006. The Creationists: From Scientific Creationism to Intelligent Design, Expanded Edition. Cambridge, MA: Harvard University Press.

Pember, Mary Annette. 2007. "Farewell to the Chief." Diverse Issues in Higher Education 24(4):18-20.

Perrin, Andrew J. 2005. “National Threat and Political Culture: Authoritarianism, Antiauthoritarianism, and the September 11 Attacks." Political Psychology 26(2):167-194.

Polletta, Francesca. 1998. “'It was like a Fever ...' Narrative and Identity in Social Protest." Social Problems 45(2):137-159.

Rosenstein, Jay. 2001. "In Whose Honor?: Mascots and the Media." Pp. 241-256 in Team Spirits: The Native American Mascots Controversy, edited by Richard C. King and Charles Fruehling Springwood. Lincoln, NE: University of Nebraska Press.

Scheff, Thomas J. 2005. "The Structure of Context: Deciphering Frame Analysis." Sociological Theory 23(4):368-385.

Silva, Eric O. 2007. “Public Accounts: Defending Contested Practices." Symbolic Interaction 30(2):245-265. American Press.
Skocpol, Theda, (ed.). 1984. "Emerging Agendas and Recurrent Strategies in Historical Sociology." Pp. 356-391 in Vision and Method in Historical Sociology. New York: Cambridge University Press.

Snow, David A. 2004. “Framing Processes, Ideology, and Discursive Fields." Pp. 380-412 in The Blackwell Companion to Social Movements, edited by David A. Snow, Sarah A. Soule, and Hanspeter Kriesi. Oxford: Blackwell Publishing.

Snow, David A. and Robert D. Benford. 1988. "Ideology, Frame Resonance, and Participant Mobilization." International Social Movement Research 1:197-217.

Snow, David A. and Robert D. Benford. 1992. "Master Frames and Cycles of Protests." Pp. 133-155 in Frontiers in Social Movement Theory, edited by Aldon D. Morris and Carol McClurg Mueller. New Haven, CT: Yale University Press.

Snow, David A. and Sarah A. Soule. 2010. A Primer on Social Movements. New York: W.W. Norton \& Company.

Spindel, Carol. 2002. Dancing at Halftime: Sports and the Controversy over American Indian Mascots. New York: New York University Press.

Staurowsky, Ellen J. 2004. “Privilege at Play: On the Legal and Social Fictions That Sustain American Indian Sport Imagery." Journal of Sport and Social Issues 28(1):11-29.

Staurowsky, Ellen J. 2007. "'You Know, We Are All Indian': Exploring White Power and Privilege in Reaction to the NCAA Native American Mascot Policy." Journal of Sport and Social Issues 31(1):61-76.

Steinberg, Marc W. 1999. “The Talk and Back Talk of Collective Action: A Dialogic Analysis of Repertoires of Discourse among Nineteenth-Century English Cotton Spinners." The American Journal of Sociology 105(3):736-780.

homson, Irene Taviss. 2010. Culture Wars and Enduring Silva, Eric O. 2013. “Levels of Disagreement Over Contested Practices.” Qualitative Sociology Review 9(4):68-83. Retrieved Month, Year (http://www.qualitativesociologyreview.org/ENG/archive_eng.php). 